\title{
Performance of Eight Switches Based Unified Power Quality Conditioner for Enhancing the Quality of Power Using Intelligent Controller
}

\author{
S. Ilankannan* and R. Francis \\ Department of Electrical and Electronics Engineering, Annamalai University, India
}

\begin{abstract}
Article Type: Article
Article Citation: llankannan S, Francis R. Performance of eight switches based unified power quality conditioner for enhancing the quality of power using intelligent controller. Indian Journal of Science and Technology. 2020; 13(04), 453-459. D0I: 10.17485/ ijst/2020/v013i04/149592
\end{abstract}

Received date: March 13, 2019

Accepted date: April 2, 2019

*Author for correspondence: $S$. Ilankannan ilankannansasikala@ gmail.com 9 Department of Electrical and Electronics Engineering, Annamalai University, India

\begin{abstract}
Objective: This study presents the unified power quality conditioner (UPQC) which is based on eight switch converter for dropping the total harmonic distortion. Alleviation of power quality is accomplished by power fed to the DC link of the converter and regulates the power using intelligent controller. Methods: The function of UPQC is determined by how fast and precisely compensation signals are estimated. The UPQC has presented for reducing the coupling problem by the presence of switching leg. In the distributed system needs to explain the approaches for standard supply voltage droop and voltage swell. Findings: The harmonics is reduced and produces the dynamic response in eight switch converter using genetic algorithm (GA). Application/ improvements: In the distribution system eight switch converter based UPQC has generated the steady state and dynamic process of control in nonlinear load and/or utility voltage conditions is implemented in MATLAB Simulink.
\end{abstract}

Keywords: Unified Power Quality Conditioner (UPQC), Genetic Algorithm (GA), Total Harmonic Distortion (THD).

\section{Introduction}

In allocation scheme, the impact of power quality is increased because of more harmonic distortion due to nonlinear loads. The distortion occurred in the way of harmonics, notching, and inter harmonics. Various responsive loads, for instance microcontroller based AC/DC drive with working condition, decrease the voltage sag and swell condition. In automation industry utilize the power electronic load. The power distortion is reduced by using both the active and passive filter. The power to be distributed to the user should be in required quantity and also its quality should be sustained. The consumers facade harmonics in inverter output and mainly occur in AC current compared to voltage, the utility inject harmonics in of FACTS devices. 
A unified power quality conditioner (UPQC) has designed and a functions of both shunt and series power converter and is connected using capacitor for regulate the voltage. The UPQC has used to reduce the power quality problem, for example, voltage harmonics, flicker, sag and swell condition, reactive power control. The projected eight switch converter utilizes the fuzzy logic control for shunt and series active power filters used a hysteresis band comparator.

In recent days, the usage of power converter has increased and more development in converter topologies. The developed power converter has used in many applications and it contribute towards increase the power quality and also burden of power system by producing the harmonics in voltage and current and enhance the reactive current. Harmonics has increased the losses and also generates the noise signal in communication channel such as voltage and current. The active power filter is mostly used in developing the power quality and also uses various functions such as load balancing, harmonics, damping, segregation and extinction, reactive power control for power factor correction and voltage maintenance [1-2]. The harmonics are decreased by using filter in olden days but proposed method utilizes the controller. The controller has to decrease the harmonic content in load current by using the genetic controller. The UPQC has to solve the power quality problems [3-4]. The DC link voltage is maintained by using the reference voltage. Other controllers, for example PI; PID, fuzzy, model predictive control and sliding mode control are used to compensate the voltage mitigation [7-10]. The UPQC has constructed equally in series and shunt converter. The series converter connects with distribution feeder using an isolation transformer [11]. The shunt converter regulates the load harmonics and series converter is proscribed. The grid current has only fundamental component and which is sinusoidal. The term power quality can be associated with the reliability of the system by the electrical utilities [12-13].

\section{Methodology}

The UPQC has to progress the Sag/Swell and Harmonics compensation across both Liner and Non Linear load in an eight switch UPQC. DC-link voltage control is implemented using genetic based sine PWM is presented to regulate sag, swell, and harmonics voltage in load converter. Tuning algorithm such as genetic control method is applied for improving better compensation in sag as well as swell. Capacitor is used in DC-Link and leg of shunt and series converter. Figure 1 demonstrates the essential demonstration of UPQC.

\subsection{Eight Switch Based UPQC}

In FACTS device such as UPQC has reduced the switches in converter and thereby decreasing the switching losses.

For the nine-switch UPQC [5-6] has less DC link voltage with fast settled the desired value while the latter has fewer losses, eight switch UPQC there is no current flow in substantial load. Figure 2 shows the overall configuration of proposed circuit. 


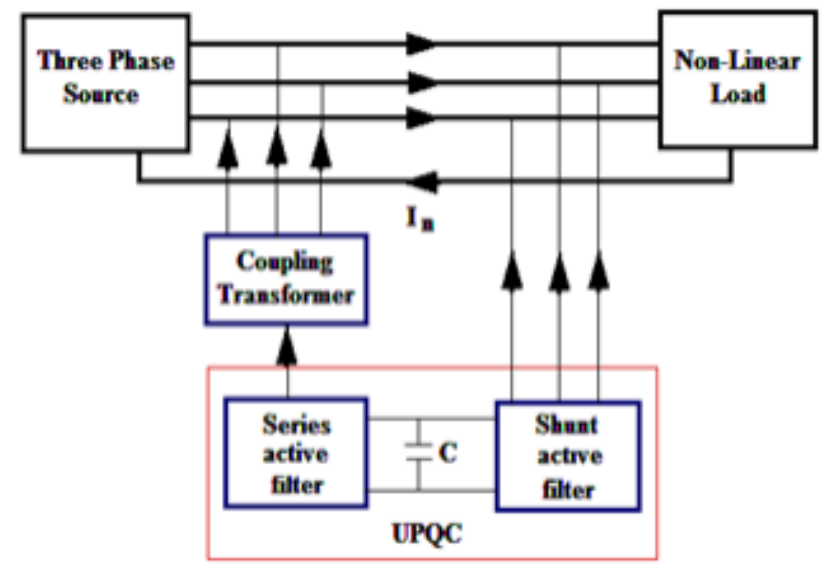

FIGURE 1. Basic representation of UPQC

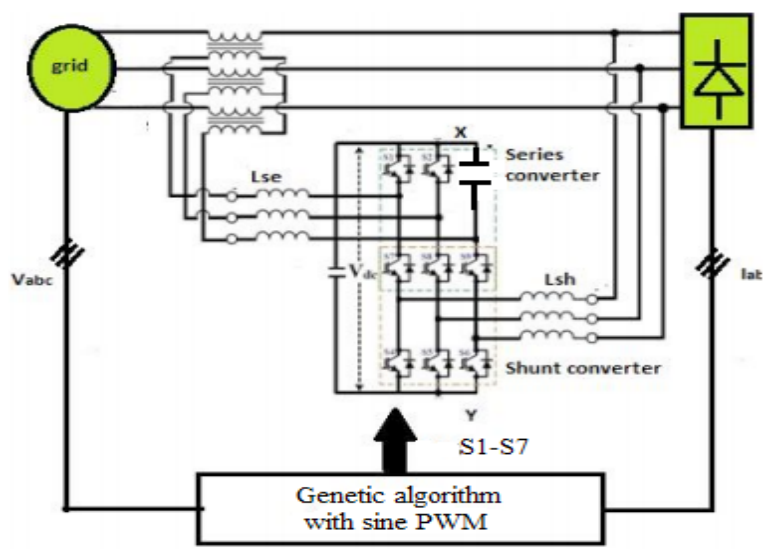

FIGURE 2. Overall configuration of proposed circuit

For upper switches reference wave is generated by using load voltage error and for lower switches the reference wave is generated by source current error. For middle switches the gate pulse is generated by using gate pulses of both upper and lower switches.

\subsection{Genetic Algorithm Controller}

The genetic algorithm (GA) is stimulated by the mechanism of regular selection where sturdier individuals would likely be the victors in a challenging environment.

Figure 3 illustrates the GA flowchart. The value of $\mathrm{kp}$ and ki has tuned by using GA. This algorithm depends on the atmosphere and development operators to appear at the preeminent solution. GA has high performance and generates local minima and congregates to finest solution. The GA has been exposed to be competent of establishing elevated performance areas in composite domains without involving the complexity associated with high dimensionality with rise descend technique on derivative information. 


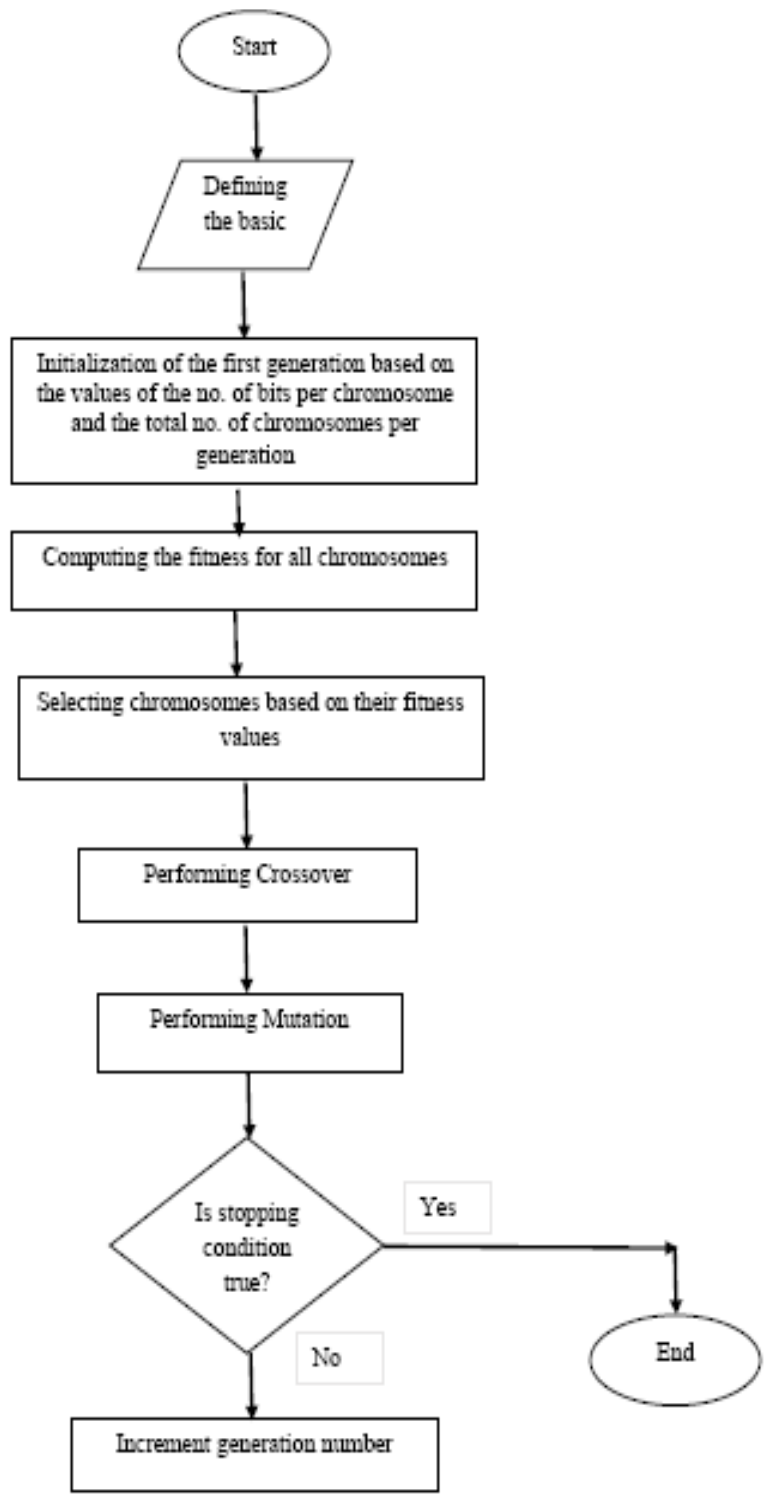

FIGURE 3. Flowchart of GA

\section{Result and Discussion}

The UPQC that was used for compensating the voltage and current and design is implemented in MATLAB Simulink. Figure 4 illustrates the simulation diagram of eight switches UPQC.

Figure 5 is shown as input voltage under sag condition in the grid. The gate pulse has been created and given for switches to turn on the switch those gate pulses are produced and offered by the gate pulse comparing switch is turned ON and OFF. Figures 6 and 7 demonstrate the output voltage and current. Figure 8 illustrates the total harmonic distortion. 


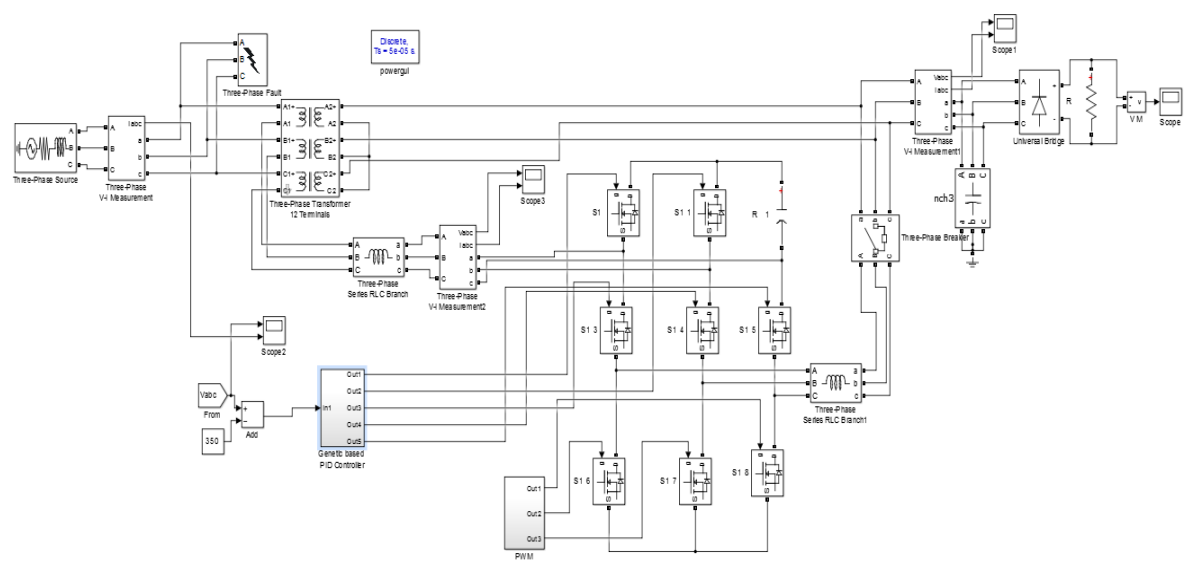

FIGURE 4. Simulation diagram of eight switches UPQC

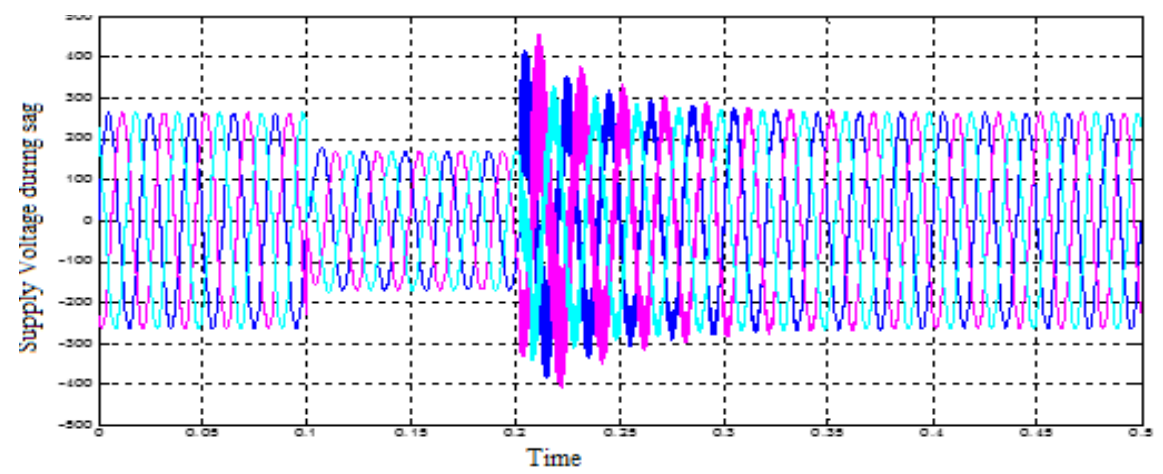

FIGURE 5. Source voltage during sag condition with eight switch UPQC

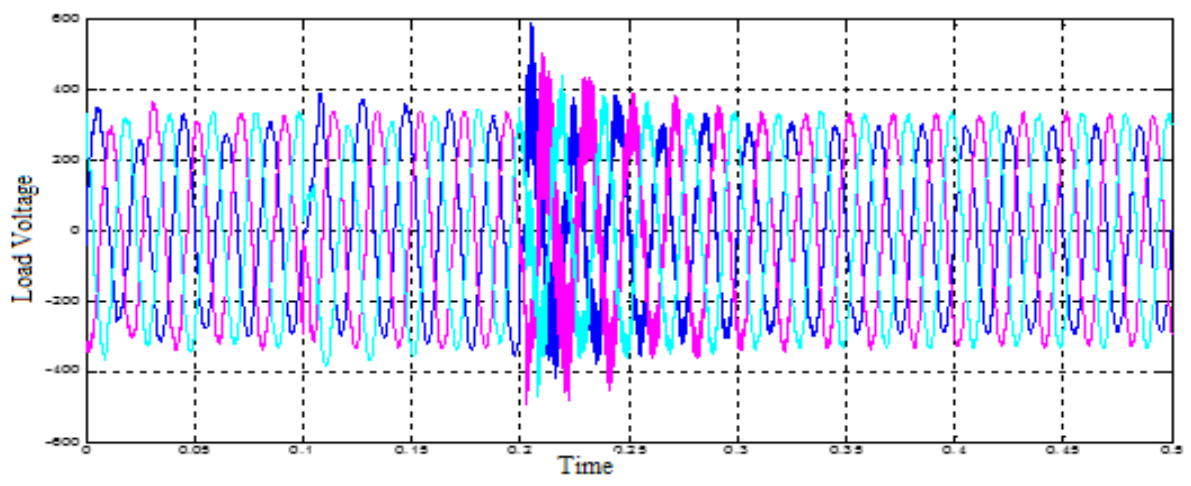

FIGURE 6. Load voltage in eight switch UPQC using GA 


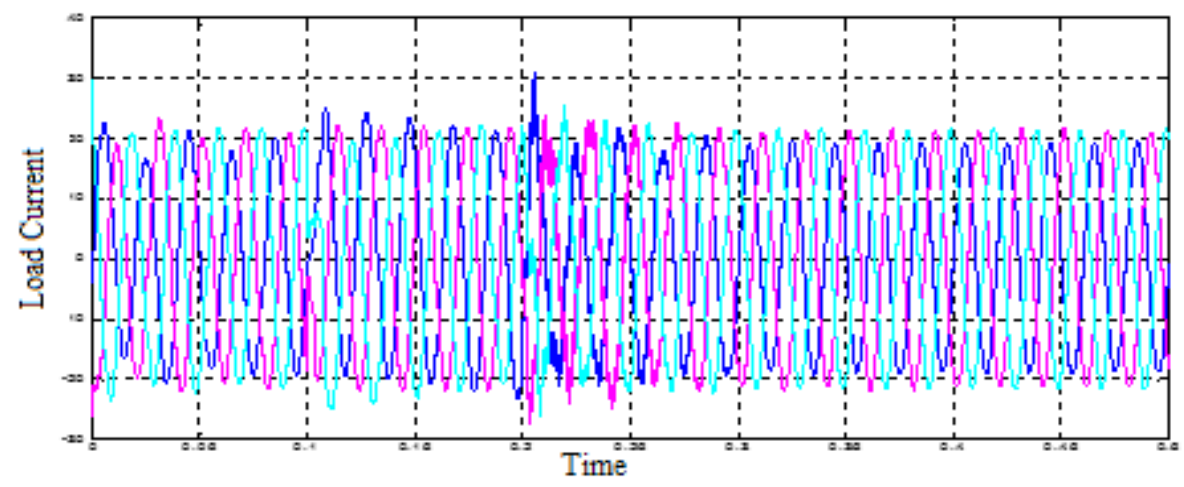

FIGURE 7. Load current in eight switch UPQC using GA

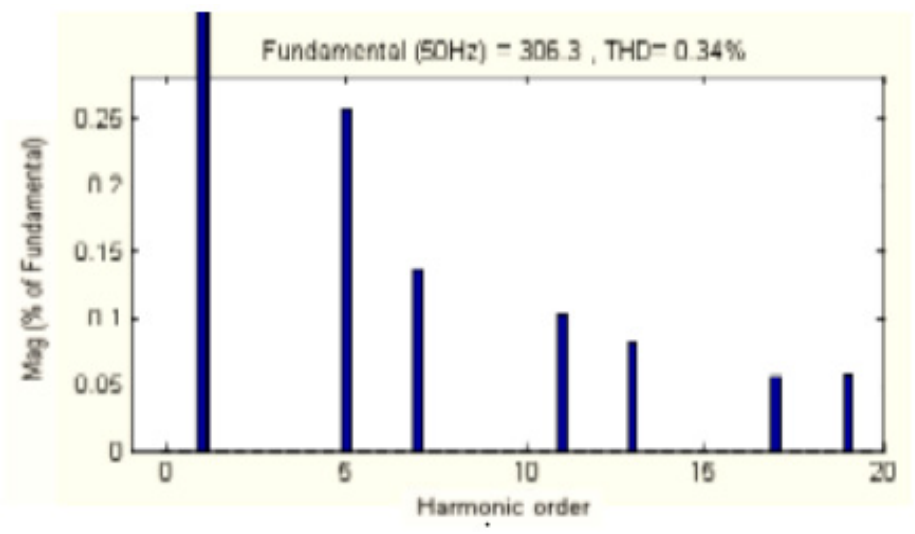

FIGURE 8. THD across non-linear load

\section{Conclusion}

This study defines the GA control method which is used in eight switch UPQC compensates the performance of voltage sag, swell, and diminish the harmonic distortion at load side. In the proposed system, the simulation results with GA prove to be more effective than conventional methods. The reconfiguration procedure includes an altered in switching status, it illuminates a larger piece of the voltage sag concern. The reactive power, harmonics at the load, voltage and current reimbursement attains the pulse width performance using optimizing control techniques. The simulation results establish that the proposed system reconfiguration method depends on the GA is proficient and sensible for improving the power quality.

\section{References}

1. Kinhal VG, Agarwal P, Gupta HO. Performance investigation of neural-network-based unified power-quality conditioner. IEEE Transactions on Power Delivery. 2011; 26(1), 431-437. DOI:10.1109/TPWRD.2010.2050706. 
2. Khadkikar V. Enhancing electric power quality using UPQC: a comprehensive overview. IEEE transactions on Power Electronics. 2011; 27(5), 2284-2297. DOI: 10.1109/TPEL.2011.2172001.

3. Bhattacharya A, Chakraborty C. A shunt active power filter with enhanced performance using ANN-based predictive and adaptive controllers. IEEE Transactions on Industrial Electronics. 2010; 58(2), 421-428. DOI: 10.1109/TIE.2010.2070770.

4. Karanki SB, Mishra MK, Kumar BK. Particle swarm optimization-based feedback controller for unified power-quality conditioner. IEEE transactions on Power Delivery. 2010; 25(4), 28142824. https://scholar.google.com/citations?user=WYjDoa0AAAAJ\&hl=fil

5. Zhang L, Loh PC, Gao F. An integrated nine-switch power conditioner for power quality enhancement and voltage sag mitigation. IEEE Transactions on Power Electronics. 2011; 27(3), 1177-1190. http://pgembeddedsystems.com/securelogin/upload/project/IEEE/15/PG2012PE95/ an_integrated_nine-switch_power_conditioner_for_power_quality_enhancement_and_ voltage_sag_mitigat.pdf

6. Rauf AM, Sant AV, Khadkikar V. A novel ten switch topology for unified power quality conditioner. IEEE Transactions on Power Electronics. 2016; 31(10), 6937-6946. DOI 10.1109/ TPEL.2015.2509510.

7. Chauhan RK, Hasan M, Pandey JP. Intelligent control model to enhance the performance of unified power quality conditioner. Journal of Intelligent \& Fuzzy Systems. 2018; 1-14. DOI:10.3233/jifs-169785.

8. Patjoshi RK, Kolluru VR, Mahapatra K. Power quality enhancement using fuzzy sliding mode based pulse width modulation control strategy for unified power quality conditioner. International Journal of Electrical Power \& Energy Systems. 2017; 84, 153-167. http://dx.doi. org/10.1016/j.ijepes.2016.05.007

9. Jayalakshmi D, Sankar S, Venkateshkumar M. An analysis of load management system by using unified power quality conditioner for distribution network. In: Emerging Trends in Expert Applications and Security. Springer: Singapore. 2019; 261-272. https://link.springer.com/chapt er/10.1007\%2F978-981-13-2285-3_32

10. Khadem SK, Basu M, Conlon MF. Capacity enhancement and flexible operation of unified power quality conditioner in smart and microgrid network. Technological University Dublin. 2018; 1-22. https://arrow.tudublin.ie/cgi/viewcontent.cgi?article=1002\&context=dubenrep

11. Dash SK, Ray PK. Performance enhancement of PV-fed unified power quality conditioner for power quality improvement using JAYA optimized control philosophy. Arabian Journal for Science and Engineering. 2019; 44(3), 2115-2129. https://link.springer.com/article/10.1007/ s13369-018-3313-0

12. Zhang L, Loh PC. An integrated nine switch power conditioner for power quality enhancement and voltage sag mitigation. IEEE Transactions on Power Electronics. 2012; 27(3), 1-14. http:// pgembeddedsystems.com/securelogin/upload/project/IEEE/15/PG2012PE95/an_integrated_ nine-switch_power_conditioner_for_power_quality_enhancement_and_voltage_sag_mitigat. pdf

13. Lu Y, Xiao G, Wang X, Blaabjerg F, Lu D. Control strategy for single-phase transformerless threeleg unified power quality conditioner based on space vector modulation. IEEE Transactions on Power Electronics. 2016; 31(4), 2840-2849. DOI: 10.1109/TPEL.2015.2449781. 